\title{
Kicker Thyratron Experience from SLC ${ }^{*}$
}

DE91 017126

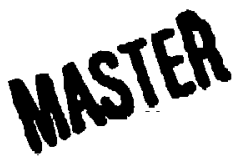

\author{
A.R. Donaldson, R.L. Cassel, and T.S. Mattison \\ Stanford Linear Accelerator Center, Stanford CA 94309 \\ L.L, Reginato \\ Lawrence Livermore National Laboratory, Livermore CA 94550
}

\section{Abstract}

The SLAC Linear Collider has five fast kickers for the damping ring injectors, extractors, and the electron extracior for the positron target that use multi-gap Deuterium-filled thyratrons. The thyratrons operate with 30 to $70 \mathrm{kV}$ anode voltages and 1 to $5 \mathrm{kA}$ currents, to delver pulses to kicker magnets with a 30 ns rise times, up to a $150 \mathrm{~ns}$ pulse widiths, at $120 \mathrm{~Hz}$. Operating and lifetime experience with several types of thyratrons and support electronics are discussed. Floating driver and power supply electronics were replaced by a ferrite choke isolator to allow grounding of the cathode support electronics with a commensurate increase in operating reliability. The construction of a 100 ns Blumlein enabled detailed measurements of the switching times for all SLC thyratrons under similar conditions. In the final focus area, the kickers dump the SLC beams after the $\mathrm{e}^{+} \mathrm{e}^{-}$collisions. These thyratrons function with $15 \mathrm{kV}$ anode voltages and up to $2 \mathrm{kA}$ currents to produce $1 / 2$ sine pulses with $=300$ ns rise times, $\Rightarrow 550 \mathrm{~ns} F W H M$, at $120 \mathrm{~Hz}$. Operating experience with these thyratrons will also be presented.

\section{SINGLE BUNCH KICKER EXPERIENCE}

The first kicker thyratron combination to operate in the SLC consisted of Blumlein configured triaxially, $Z=16.7 \Omega$ using castor oil as a dielectric and cooling medium for the thyratron. The first thyratron used in 1981 was an EG\&G HY5333, a very compact three gap tube, rated for $50 \mathrm{kV}$ and high di/dt - $17 \mathrm{kA} / \mathrm{us}$ operation. Early SLC operation required five of these pulsers. The Blumlein pulser system is still in use roday in three SLC areas [1]. The thyratron is still an EG\&C unit, but was upgraded in 1983 to a HY 5353 which is usually operated at $35 \mathrm{kV}$, switching $=4 \mathrm{kA}$ with $=30 \mathrm{~ns}$ for the 0 to $100 \%$ rise time.

The Blumlein was limited in length/height because of the intended application to about 80 ns across the base line, since the $\mathrm{e}^{+}$damping ring revolution time is $120 \mathrm{~ns}$. These parameters dictate thyratron rise time to $\ll 30$ ns for an flattop pulse. Unfontunacely, rise times were $230 \mathrm{~ns}$ resulting in a parabolic pulse shape, which then forces the jiuter performance to $1 \mathrm{~ns}$. The HY5353's are being pushed to their limit in terms of required rise time, di/dt, and jitter performance. They tvere operated at high reservoir vollages in the days of resonant charging, and squired frequent attention to avoid SLC down time. The typical approach was to nurse the tube until SLC Operations said, "OK, replace it." This they

\footnotetext{
- Work supported by US Deparment of Energs' contract DE-ACO3.
76SF005is

"Work supported by US Department of Energs' contract DE-ACO3.
765 F00515
}

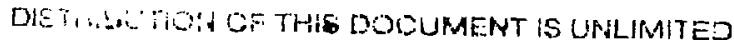
Presented at IEEE Particle Accelerator Conference, San liancisco, C.M, May 6-9,199I were reluctant to do because it could take four or five hours to accomplish. To date, HY5353 installed lifetines are $=1000$ hours rather than a reasonable value, e.g., $\approx 5000$ hours.

Currently a command charger [2] is used on the Blumlein, which charges the line in $50 \mu s$ and holds the charge for $50 \mu \mathrm{s}$ before the thyratron is triggered. It allows a higher reservoir voltage, for a rise time of $\mathbf{2 5} \mathrm{ns}$, and the pulse 10 pulse jituer is $<1$ ns. Command charging has resulted in better kicker performance with a modest increase in thyratron lifetime. The long term timing drift is canceled via a feedback system [3].

A jump increase in jitter is the first indication of a thyratron problem. Normally, jitter instability can be stopped with dc reservoir volnge adjustments, or in rare situations the dc heater voltage is increased. Decreasing the anode voltage does stop tive jitter, but that also decreases the kick angle and impairs SLC operation. When the thyratron reaches the $>1000$ hour stage of operation and a big jump of jitter occurs, it is more difficult to reduce or stop with heater or reservoir voltage adjustments. The HY5353 has a pre-ionization electrode or keep-alive (K-A) grid that is usually operated at = $50 \mathrm{~mA}$. In this regime the voltage on the electrode measures $-20 \mathrm{~V}$, and when a new thyratron is first installed, jitter is $\ll 1 \mathrm{~ns}$, but as the tube ages the jitter increases, and to reduce it the K-A current is removed by grounoing the $K$-A grid through a low impedance. This improves the jitter performance for weeks and sometime months, but eventually the $>1$ ns jitter reappears and forces another appiication of current to the K-A grid. It generally takes two or three episodes of K-A on and off before we are convinced that tube replacement is necessary. Replacement with a new or rebuilt device seems the only solution. The old unit is installed in the tess Blumlein. The rejuvenation period takes about 100 hours, the anode voltage, heater, reservoir, and K-A current are varied until the thyratron stabilizes.

Occasicnally the HY5353 will fire-through and can afror a spate of arcing destroy the output stage of the trigger driver, which indicates operation in the spark gap mode. The trigger driver has been protected from the effects of fire-through with series diode and $\mathrm{L}-\mathrm{C}$ filter. The drawback of this protection is a slower trigger rise time and consequent increase in jitter. A new output stage for the trigger generator using pulse compression has been designed and is undergoing testing. It offers a five fold speed up in the rise time from the generator while preventing reverse current from blasting the output SCR. The compressor drives the control grid with a shaper pulse to further reduce the jitter from the HY 5353. 
A thyratron engineer at EG\&G had proposed a theory that implicated cathode hot spotting, which caused the HY5353 to exhaust an area of the cathode. It then could operate in an unstable mode until a new cathode emitting area was established [4]. Another HY5353 researcher [5] theorized that the insubility was caused by grid hot spouting because of supponing evidence discovered in disassembled HYS353's. He had taken several apart and noticed bluing on the circumferences of certain control grid penetrations as if the. plasma were following a specific path, which remained fixgd for a period of operation until the beginning of jituer instability. He had disassembled thyratrons that had three bouts of instability and had found three different blued grid circumferences and matching polished areas on the anode. The two explanations are similar, and serve to indicate what has been observed with the HYS353's in the SLC Blumleins. However in a recent autopsy by EG\&O no definite evidence for either phenomena was reported. The EG\&G official version reads [6], "Gas clean-up is nol evident. Cathode deterioration is causing time jiider increase with life. Cathode deterioration after $10^{9}$ shots is normal life in our estimation." For $120 \mathrm{~Hz}$ operation, this translates to a 2300 hour lifetime. Fortunately, we have managed to wrest $\approx 2 \times 10^{9}$ shots based on operating hours, by nursing the thyratrons back to usability on the Blumlein test stand. Considering the total number of thyratrons consumed, the lifetime is $=5000$ hours, but since every unit has to be pulled out at $=1000$ hours for rehabilitation, once or twice, the confidence level for the HY5353 is $<50 \%$.

\section{TWO BUNCH KICKER EXPERIENCE}

The Blumlein pulser with its narrow pulse specifically for $\mathrm{e}^{+}$single bunch injection and extraction was ineffective for two bunch kicking in the $\mathrm{e}^{-}$damping ring. In this ring SLC needed a kicker magnet pulse with a long flatop width for the two bunches with a 60 ns separation, and rise and fall times of $\leq 30$ ns. The kicker uses two parallel thyratrons with each discharging a pair of $50 \Omega$ coaxial cables [7]. Each thyratron is coaxially enclosed. Both coaxial enclosures are housed in a tank that has a mineral oil circulation system providing a Filtered dielectric and themnal transfer. The thyratrons are EEV CX167ID's which when properly used are capable of $\leq 30 \mathrm{~ns}$ rise times for 10 to $90 \%$. The anodes work at up to $70 \mathrm{kV}$, nomally $60 \mathrm{kV}$ and each thyratron switches $1.2 \mathrm{kA}$ for a $=150 \mathrm{~ns}$ pulse. These kickers are also command charged to allow high gas pressure operation for fast switching.

In the early version of this kicker (1986), the trigger driver. reservoir, heater, and prebias supplies were at the cathode potential during the pulse. The cathode electronics package was trigger and power connected to the control racks via fiberoptic cable and high frequency transformer isolation respectively. They were not reliable, hard to diagnose, and difficult to maintain without replacing the package and thyratron as an ensemble. Our early operating experience of the CX1671D is masked by the numerous false alarms caused by the triggesing and supply stability problems with the electronics package.
In 1989 an isotation choke was designed so that the trigger driver, reservoir, heater, and prebias supplies could be located at ground. This choke was designed for a $5.6 \times 10^{-3} \mathrm{~V}-\sec$ flux swing. It consists of two stacked toroids of CMD5005 matcrial with $2 \mathrm{sq}$. in. of area. All of the thiygaron trigger,

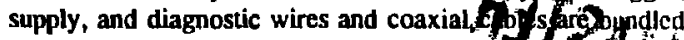
together with an overall jacket diameter of $1 / 2$ illoty th thon nine turns of this composite cable are wound onto the $\mathrm{St}(\mathrm{t} / \mathrm{d}$ toroids. The choke presents an impedance approximately 50 to 100 times the $25 \Omega$ load on the thyratron cathode, or $\approx 20 \mathrm{~A}$ pulsed path to ground compared to the $1200 \mathrm{~A}$ load current. Turn to turn voltage can be as high as $4.4 \mathrm{kV}$ in the circulating oil dielectric, hence a special nine holed nylon guide is placed into the toroid hole so that each tum is always physically isolated from adjacent turns. The choke is biased via an air core inductor of $100 \mu \mathrm{H}$ connected from the cathode to ground. The core bias is $=\mathbf{3 . 5} \mathrm{A}$, determined by the $R_{\mathrm{dc}}$ of the air core coil, and supplied parasitically from the dc heater supply. The resistance of the air coil was kept low to insure this 3.5 A bias. Eliminating the fiber-optic uriggering roduced the jitter dramatically. The reliability of the commercial heater and reservoir supplies with hard wired diagnostics resulted in a major reduction of kicker downume. These isolation chokes have been in use for almost two years, finally offering a true idea of the CX1671D's performance and lifetime.

Combining the early CX1671D experience with the latest data indicates the nominal is lifetime is $\mathbf{5 5 0 0}$ hours with a confidence level of $70 \%$ and increasing.

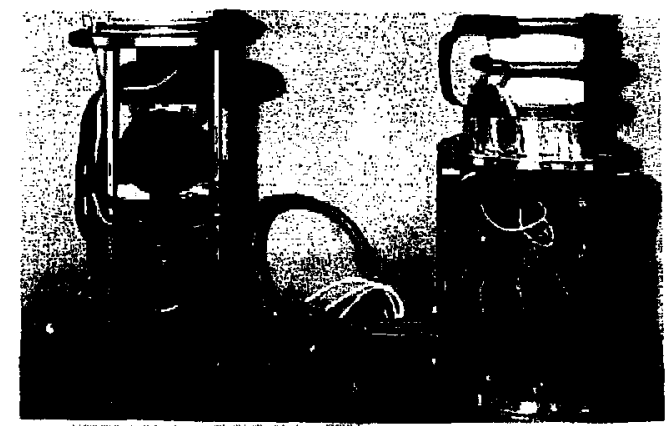

Figure 1. Comparison of the floating electronics package (left) with the isolation choke package (right).

\section{LONG BLUMLENN RESULTS}

SLC obviously needs fast and reliable thyratrons for kickers. An investigation into the suicability of our present thyratrons and a quest for better types led to the constraction of a $100 \mathrm{~ns}$ Blumlein using water (LCW) as a dielectric to kecp the physical length to a reasonable size. The Blumlein had two sets of internal electrodes, so that with a modest effort the impedance ci uld be changed from $12.5 \Omega$ to $25 \Omega$ for switching point impedances of $6.25 \Omega$ and $12.5 \Omega$. This would allow variation of the $R$ in the $L / R$ time constant. It could also ofler an idea of whether the $\mathrm{L}$, or the ionization time of the thyratron dominated the fall time. The thyratron was mounted 
excernally and coaxially beneath the line with forced air cooling to allow quick replacement and measurement access. The anode voltages were typically $25 \mathrm{kV}$, somewhat less than the actual operating voltages. The line was tested using various spark gap configurations, and then reworked to reduce the lead inductance from the center conductor to anode to $40 \mathrm{nH}$.

The data in Table 1 was taken by discharging the line into a resistive load of either $25 \Omega$ or $12.5 \Omega$, and measuring the fall time (10 to 90\%) at the anode of the switching device. In a few cases, no measurements were taken. The thyratrons lested were or had been used in other applications at SLAC and except for the new CX2025X, may have been previously used.

The CX1574C is the thyratron for the final focus kicker and has a 5100 hour average lifetime. Il was selected for testing because of good lifetime experience, compact size (one gap), and a $15 \mathrm{kA}$ current rating. The CX1536A had been used with some success in the klystron modulators on the linear accelerator where they had averaged $\boldsymbol{m} 8000$ hours. The tube is a rather compact two gap device with a $10 \mathrm{kA}$ rating.

\begin{tabular}{|c|c|c|c|c|}
\hline \multicolumn{3}{|l|}{$\mathrm{Z}_{\text {Line }}=$} & \multirow{2}{*}{$\begin{array}{c}25 \Omega \\
\text { fall in ns }\end{array}$} & \multirow{2}{*}{$\begin{array}{r}12.5 \Omega \\
t \text { fall in ns }\end{array}$} \\
\hline SWITCH & ht." & gaps & & \\
\hline Spark Gap & $<1$ & 1 & - & 12 \\
\hline CX1574C & 8.4 & $I$ & $=$ & 42 \\
\hline CX1536A & 12.6 & 2 & $=$ & 60 \\
\hline CX1671D & 13.5 & 3 & $=$ & 60 \\
\hline HY5353 & 5.8 & 3 & 14 & 151020 \\
\hline CX2025X & 8.7 & 4 & 18 & 20 \\
\hline
\end{tabular}

Table 1. Comparison of fall times using the Long Blumlein.

Since the CX1671D was being applied in the two bunch kicker, it could be considered a candidale for Blumlein use as well. It is a somewhat long wbe with three gaps and a modest $3 \mathrm{kA}$ rating, probably marginal for a $12.5 \Omega$ Blumlein and $4 \mathrm{kA}$ switching point current.

For the HY5353, we needed actual validation, since it had been in use for six years as the Blumlein thyratron. It is the shortest three gap and most compect of the thyratrons tested with a $5 \mathrm{kA}$ rating for $\mu \mathrm{s}$ width pulses, and conceivably capable of $10 \mathrm{kA}$ at the $100 \mathrm{~ns}$ widh. The Blumlein was changed from $12.5 \Omega$ to $25 \Omega$ and the fall times for the thyratrons decreased by only $10 \%$. This discovery indicated the fall is not $L / R$ domirated but is mainly determined by the thyratron ionization time. Data in Table 1 implies this, since the one gap CX1574C has a two times longer fall time than the three gap HY5353. Data below in Table 2 for the HY5353 offers the same implication, i.e., increase the gas pressure and decrease the ionization time. Furthermore, the K-A grid could be prepulsed with additional reductions in fall time.

\begin{tabular}{|l|l|l|l|l|}
\hline Reservoir Voltage (V) & 4.0 & 4.5 & 5.0 & 5.5 \\
\hline \hline HY5353 t fall $10-90$ (ns) & 16 & 14 & 12 & 10 \\
\hline
\end{tabular}

Table 2. Comparison of fall times vs reservoir voltage.

The CX2025X is a recent (1988) thyratron design from EEV intended as very fast, high di/dt switch, with $100 \mathrm{kV}$ and $15 \mathrm{kA}$ specifications. The results show it as the only serious competition for the HY5353. A redesigned thyratron housing for the SLC Blumlein with a CX2025X will permit additional testing and an eventual reliability run.

\section{SUMMARY AND PROSPECTS}

The long Blumlein tests offered a validation that the HY5353 was the only production thyratron for the single bunch kicker applications. Which unfortunately is still an SLC handicap, since it is a short lived and cranky thyratron once past the 1000 hour stage. The possible replacement a CX2025X could possibly exhibit better total performance without the eccentricities of the HY5353, once the merhanical changes to the thyratron housing on the Blumlein are accomplished. The double bunch kickers use a thyratron pair, which are far more reliable especially after the replacement of the flnating electronics package, since the tubes are quite suited to kicker parameters, The final focus kickers are also correctiy tubed for the present with additional work planned to reduce the reverse voltage and curnent for even longer lifetime.

\begin{tabular}{|c|c|c|c|c|}
\hline KICKER & Units & 1 bunch & 2 bunch & FF $1 / 2$ sine \\
\hline Thyratron & ea & HY5353 & CX1671D & CX1574C \\
\hline t PW & nS & 80 & 150 & 540 \\
\hline pulse/p'lse jitter & $\overline{n s}$ & $\leq 1$ & $\leq 0.5$ & $\leq 5$ \\
\hline V anode & $\mathbf{k V}$ & $\overline{35}$ & 70 & $+12 \&-2$ \\
\hline I Anode & $\mathbf{k A}$ & 4 & 1.4 & $+2 \&-0.4$ \\
\hline$t_{\text {fall }} 10-90$ & ns & 25 & 30 & 300 \\
\hline PRR & $\mathrm{Hz}$ & 120 & 120 & 120 \\
\hline Average Life & $\mathrm{hr}$ & 5000 & 5500 & 5100 \\
\hline Confidence & $\%$ & $<50$ & $\overline{70}$ & 80 \\
\hline
\end{tabular}

Table 3. Comparison of thyratron parameters and lifetimes.

Table 3 summarizes our operating experience with the three kicker thyratrons. Based on the tests done with the long Blumlein, SLC does have the right thyratrons in the right locations. It is also possible that the Blumlein pulser can be improved by using the CX2025X in place of the HY5353.

\section{ACKNOWLEDGMENTS}

The authors are indebted to the following people for quality suggestions, lively discussion, and hard work: M. Artusy, G. Aske, D. Briggs, G. Bowden, D. Gough, S. Hewit,, J. Krzaszczak, M. McCoy, and D. Williams who has patienuly nursed a his share of sick and dying thyratrons.

\section{REFERENCES}

[1] F. Bulos et al., "Some Fast Beam Kicker Magnet Systems at SLAC." PAC Record 87CH2837-9. Washington, D.C., March 1987, pp. 1884-6.

[2] R.L. Cassel and M. Nguyen, "Kicker Pulsed Charger," XTP16, this conference.

[3] D.E. Gough ef al., "The Timing and Diagnostics Systems of the Kicker Magnet Pulsers for SLC," XTP24, this conference.

[4] R. Caristi, Private Communication November 1988.

[5] G. McDuff, Private Communication April 1991.

16] I. Murachver, Private Communication, August 1990.

[7) L. Bartelson et al., "Kicker for the SLC Electron Damping Ring," PAC Record 87CH2837-9, Washington, D.C.. March 1987. pp. 1582-4. 


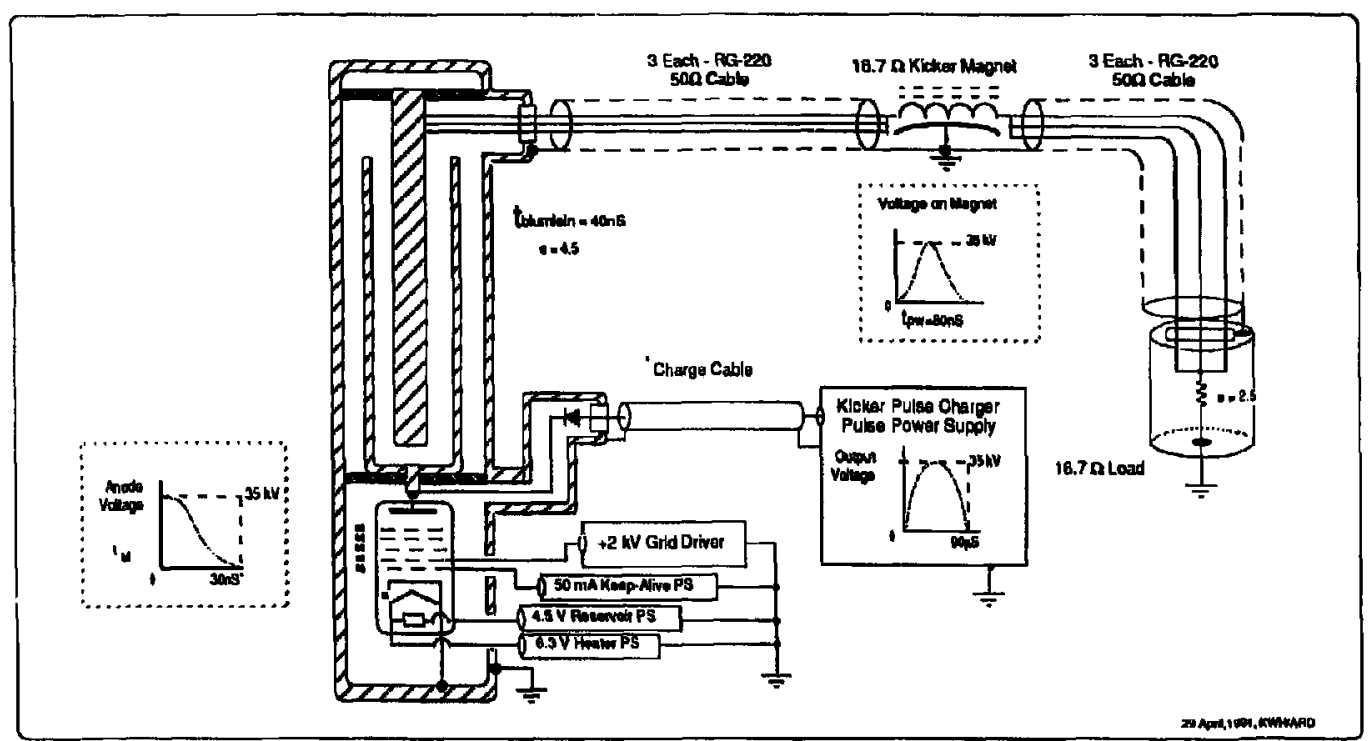

Simplified Schematic of SLC Single Bunch Blumlein Kicker System

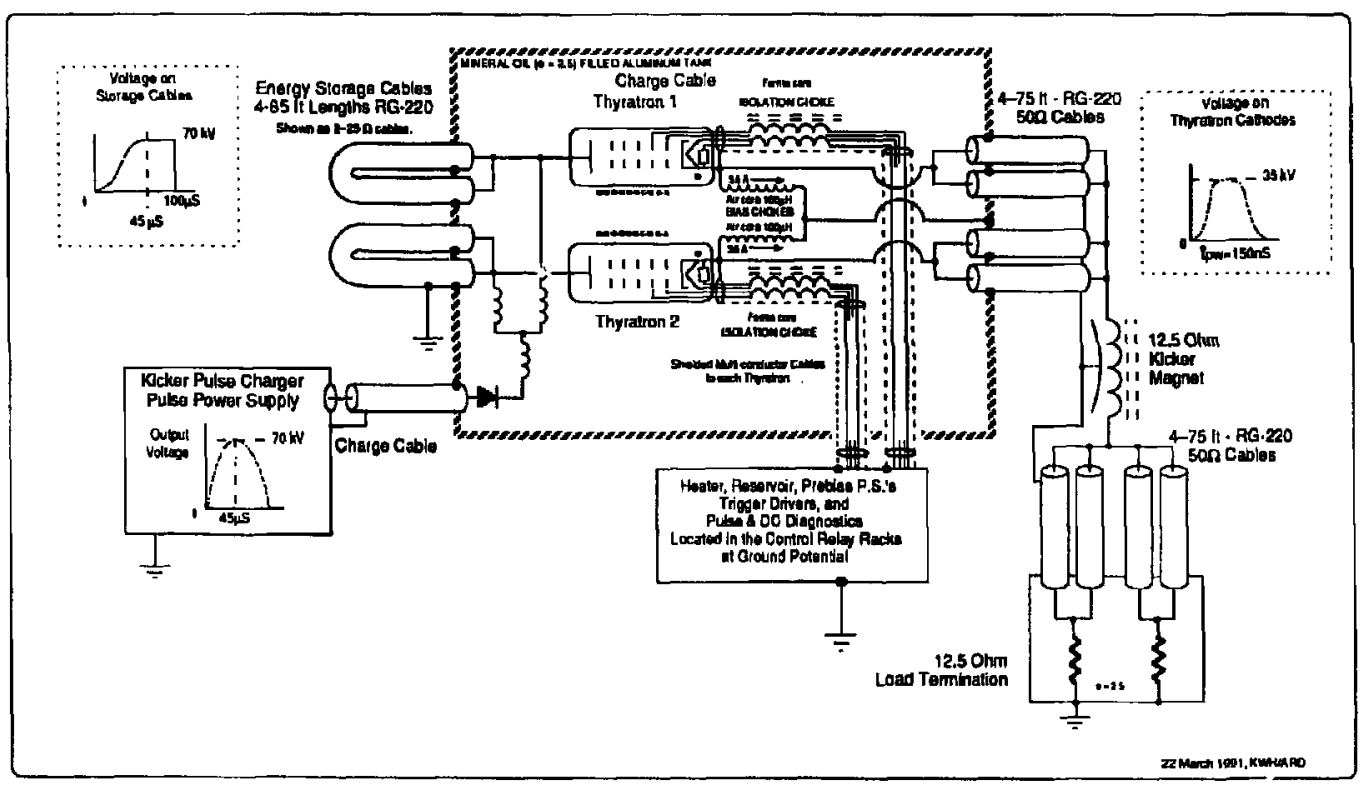

Simplified Schematic of SLC Two Bunch Kicker System 